\title{
The interplay of gender, social context, and long-term unemployment effects on subjective health trajectories
}

\author{
Laura Altweck ${ }^{1 *}$, Stefanie Hahm¹, Holger Muehlan', Tobias Gfesser², Christine Ulke², Sven Speerforck², \\ Georg Schomerus ${ }^{2}$, Manfred E. Beutel ${ }^{3}$, Elmar Brähler ${ }^{3}$ and Silke Schmidt ${ }^{1}$
}

\begin{abstract}
Background: While a strong negative impact of unemployment on health has been established, the present research examined the lesser studied interplay of gender, social context and job loss on health trajectories.

Methods: Data from the German Socio-Economic Panel was used, which provided a representative sample of 6838 participants. Using latent growth modelling the effects of gender, social context (East vs. West Germans), unemployment (none, short-term or long-term), and their interactions were examined on health (single item measures of self-rated health and life satisfaction respectively).

Results: Social context in general significantly predicted the trajectories of self-rated health and life satisfaction. Most notably, data analysis revealed that West German women reported significantly lower baseline values of selfrated health following unemployment and did not recover to the levels of their East German counterparts. Only long-term, not short-term unemployment was related to lower baseline values of self-rated health, whereas, in relation to baseline values of life satisfaction, both types of unemployment had a similar negative effect.
\end{abstract}

Conclusions: In an economic crisis, individuals who already carry a higher burden, and not only those most directly affected economically, may show the greatest health effects.

Keywords: Unemployment, Health, Life satisfaction, Social context, Gender, Panel data, Growth modelling

\section{Background}

For most people, employment is the foundation to a stable life, enabling us to maintain our sense of purpose and shape our daily life. Beyond the apparent financial strain [1], unemployment can lead to a change in a person's time structure, their social relationships and in their identity [2, 3]. The non-financial costs of unemployment often have a stronger association with wellbeing during this time [4]. Overall, the negative relationship between unemployment and health is widely

\footnotetext{
* Correspondence: laura.altweck@uni-greifswald.de

'Department of Health and Prevention, University of Greifswald, Robert-Blum-Str. 13, 17489 Greifswald, Germany

Full list of author information is available at the end of the article
}

reported in the literature [5-10]. However, what if a whole group of society faces unemployment simultaneously, as seen currently during the COVID-19 crisis?

The set-point theory posits that in the short-term subjective well-being fluctuates following major life events and in the long-term values return to a predetermined 'set point' [11-13]. In regards to unemployment, an improvement in health is generally seen after reemployment (e.g., [3]). However, Clark et al. [6] examined the long-term effect of job loss and reemployment on life satisfaction and found that some people did not return to their baseline values many years after the end of their unemployment.

(C) The Author(s). 2021 Open Access This article is licensed under a Creative Commons Attribution 4.0 International License, which permits use, sharing, adaptation, distribution and reproduction in any medium or format, as long as you give appropriate credit to the original author(s) and the source, provide a link to the Creative Commons licence, and indicate if changes were made. The images or other third party material in this article are included in the article's Creative Commons licence, unless indicated otherwise in a credit line to the material. If material is not included in the article's Creative Commons licence and your intended use is not permitted by statutory regulation or exceeds the permitted use, you will need to obtain permission directly from the copyright holder. To view a copy of this licence, visit http://creativecommons.org/licenses/by/4.0/ The Creative Commons Public Domain Dedication waiver (http://creativecommons.org/publicdomain/zero/1.0/) applies to the data made available in this article, unless otherwise stated in a credit line to the data. 
The effects of unemployment on different aspects of health are often used interchangeably. Unemployed individuals have reported significantly lower mental health, subjective physical health and marital, family and life satisfaction compared to their employed counterparts [3, 14], but a non-significant relationship with objective physical health [3] or psychiatric caseness [14] is seen. To address these differential effects of job loss, the present study draws on the World Health Organization's [15] holistic definition of health - i.e. physical, mental, and social well-being as opposed to the mere dichotomy of ill versus healthy - and examines two different aspects of general health status: self-rated health (a oneitem proxy for subjective health) and life satisfaction (cognitive aspect of well-being).

\section{Short- versus long-term unemployment}

Another aspect to consider is short-term as opposed to long-term unemployment, where the latter is largely associated with worse health $[3,6,16-18]$. While individuals who had experienced repeated unemployment compared to those who had never been unemployed reported significantly worse mental health and lower life satisfaction [19], individuals who had experienced single unemployment compared to the other groups (i.e., repeated unemployment or no experience at all) only significantly differed in their satisfaction with income and employment [20]. One can infer that short-term unemployment may impact directly on related matters like finances, while a broader impact on life manifests following longer or repeated experience of unemployment.

Long-term unemployment has often been defined as short as six months [21] or one year or more [22]. While the length of unemployment worsens the effects of job loss on health, this effect does not appear to remain constant. Within the first year of unemployment mental health scores continually fluctuate between deterioration and recovery [7], while after a few years an habituation effect is seen and the increase in health risks plateau [23]. These findings suggest that six to 12 months is not sufficient to adjust to unemployment and for its effect to become fully evident. Therefore, in the current study we defined long-term unemployment as being registered unemployed in two consecutive years.

Lastly, McKee-Ryan et al.' [3] meta-analysis showed that the effect of longer unemployment on subjective physical health was stronger than on life satisfaction. So we propose the following:

- H1: The effects of a) long-term versus short-term unemployment on self-rated health will be more negative and b) the effects of short-and long-term unemployment will be similar on life satisfaction.

\section{Social context}

Returning to the overarching research interest: how does mass unemployment affect the well-being in a population? Data from previous occurrences of mass unemployment, help draw parallels to similar circumstances: like the global financial crisis in 2009, the European refugee crisis in 2015 or the current COVID19 crisis [24]. The present study examines unemployment immediately following the German reunification in 1989/1990. This data is particularly useful in the investigation of unemployment, because in this period East Germans were confronted with a major change in economic policies and their employment system. The government of the former socialist East Germany emphasized the importance of the work force and it had been every citizen's basic right but also their obligation to take up employment [25]. After reunification, most East Germans faced involuntary retraining from the job centre, a change in workplace or unemployment. The 1991 annual unemployment statistic by the German Federal Employment Agency recorded levels of $10.3 \%$ in East Germany and so nearly double to the $6.3 \%$ in West Germany [26]. In Struck et al.' [27] study, 33\% of East Germans reported a change in their job role shortly after reunification and $69 \%$ reported a change in their workplace, while Mayer [28] reported that $40 \%$ had experienced job loss by 1995. In contrast, in West Germany a stable rate of unemployment was present and affected the same groups continuously [29].

In sum, following the reunification unemployment presented differently in East versus West Germany: in the former, unemployment was unexpected and forced on a large scale (e.g., through plant closures), while the latter group grew accustomed to unemployment and the low prospects of reemployment. Then, especially in the West German group the reciprocal relationship between unemployment and health should not be highlighted. Analyses with panel data have shown that unemployed individuals already reported lower health levels prior to becoming unemployed [30] and may have become unemployed as a result of their lower health. In the East German sample, it is less likely that the relationship between unemployment and health would have been reciprocal, because first, unemployment did not exist in former East Germany and so was a novel experience, and second, it presented itself on a large scale and was unpredictable.

High regional unemployment has also been found to be associated with significantly more functional somatic symptoms [31], psychological symptoms [32], and lower subjective well-being [33]. Turner [34] for instance found that in communities with medium to high unemployment rates, current unemployment was associated with higher levels of depression and physical illness. 
However high regional unemployment in general is associated with lower health in both employed and unemployed individuals living in the region $[3,35]$ and instead it may be the prospect of reemployment that plays a greater role [36]. Thus we propose that:

\section{- H2: Unemployment will have a stronger impact on health in the East compared to the West German sample.}

\section{Gender and unemployment}

In former East Germany the discrepancy in income and employment rates between men and women was low [37] and women were encouraged and supported to easily combine their roles as mother, wife and worker [38]. In contrast, in West Germany, in the end 1980s, only $50 \%$ of women were in employment [39] and instead most were housewives. After reunification, East German women faced grave discrimination in the more traditionally gender-role oriented West German employment system [27] and faced twice as much job insecurity compared to their male counterparts(female: $31.4 \%$, male: $13.1 \%$ [18]).

In general, men assign greater importance to work, which can be explained by traditional gender roles: men are the breadwinners of the family and bear the responsibility of providing for them, while women care for the children and run the household. So along these lines it would be 'easier' for women to become unemployed, because, first, they would likely not be the main source of income, and, second, they could transition to the role of housewife, instead of a vacuum of 'no employment'. By comparison, men would experience the effects of no longer fulfilling their traditional roles. Van der Meer [40] found that while men gain most of their status from their job, women attain their status from several sources. Forret et al. [41] further showed that men with children are more likely to see unemployment as a defeat, while women perceive it as an opportunity.

While women's participation in the labour market even now is significantly lower than men's [42], traditional gender roles are changing. Strandh et al. [43] purported that the associations between unemployment, gender and psychological distress are dependent on the social context and compared samples from Ireland and Sweden. They found that compared to Irish men, women reported lower distress following unemployment, whereas Swedish, unemployed women reported greater distress than their male counterparts. The authors explained that Sweden has a large female labour force and the society is strongly defamilised, whereas the opposite is the case in Ireland, which follows more traditional gender roles. Hammarström et al. [44] also studied unemployment in a Swedish sample and similarly found no gender effect. As East German women after reunification similarly did not embody traditional gender roles and had a high participation in the labour market, this group is comparable to the Swedish samples. In this vein we propose that:

\section{- H3: The interaction effect of unemployment having a stronger impact on health in the East versus West German sample should be stronger in the female compared to the male sample.}

\section{Methods \\ Sample}

Data from the Core-Study of the German SocioEconomic Panel (SOEP) was used. This is an annual representative longitudinal study of private households from 1984 until present $[45,46]$. While some core constructs are measured annually (e.g., household structure, employment history, income), others are measured once or at less frequent intervals (e.g., self-rated health). Data from the GSOEP has been used by other research groups to examine the association between unemployment and life satisfaction (e.g., $[6,8])$. However, first, the effects on self-rated health and, second, the specific effects of unemployment after German reunification on self-rated health and life satisfaction has not been investigated with this data.

The GSOEP first collected data from families in West Germany and is particularly interesting for the current study as a group of East German participants joined directly after reunification. Participants outside of working age - i.e., 1865 years - in 1992 and with missing data were excluded $\left(N_{\text {to- }}\right.$ tal $\left.=13,397, N_{18-65 y e a r s}=11,684\right)$. As a result, the current analyses were run on a sample of 6838 participants $\left(N_{\text {East }}=\right.$ 2493, $N_{\text {West }}=4345$ ). The demographics in Table 1 show large differences between context and gender. Compared to male West Germans, the East German participants reported a significantly lower household income, were older, more likely to be in a partnership, less likely to have completed middle but more likely to have completed high education, more likely to be in no or part-time employment, and were more likely to be unemployed from 1991 to $1996(p<.05)$. Female compared to male West Germans were also significantly older and reported a lower household income, but generally showed lower education rates, and more likely to be in no or part-time employment $(p<.05)$. The unemployment rates for West German women fluctuated and they were more likely to be unemployed in 1993 and 1994, but less likely in the other years.

\section{Measures}

All methods were performed in accordance with the relevant guidelines and regulations (Declaration of Helsinki). Self-rated health was measured using the item 
Table 1 Socio demographics by social context, and gender: Means (Range), SD / Frequencies (Percent)

\begin{tabular}{|c|c|c|c|c|}
\hline & \multicolumn{2}{|l|}{ East } & \multicolumn{2}{|l|}{ West } \\
\hline & Female & Male & Female & Male \\
\hline Age & $\begin{array}{l}40.05(18-65) \\
S D=12.77\end{array}$ & $\begin{array}{l}40.23(18-65) \\
S D=12.79\end{array}$ & $\begin{array}{l}39.13(18-65) \\
S D=13.29\end{array}$ & $\begin{array}{l}38.31(18-65) \\
S D=13.40\end{array}$ \\
\hline Household income & $\begin{array}{l}1372.20(179-3835) \\
S D=564.18\end{array}$ & $\begin{array}{l}1459.82(179-3835) \\
S D=592.58\end{array}$ & $\begin{array}{l}2056.28(0-10,737) \\
S D=1066.66\end{array}$ & $\begin{array}{l}2158.08(256-10,737) \\
S D=1004.38\end{array}$ \\
\hline \multicolumn{5}{|l|}{ Partnership Status } \\
\hline In partnership & $1273(73.25)$ & $1242(73.02)$ & $1992(68.06)$ & $1818(63.06)$ \\
\hline Not in partnership & 465 (26.75) & 459 (26.98) & 935 (31.94) & $1065(36.94)$ \\
\hline \multicolumn{5}{|l|}{ Education } \\
\hline Low & $1234(69.40)$ & $1100(64.21)$ & $3356(84.36)$ & $3129(78.03)$ \\
\hline Middle & $66(3.71)$ & $215(12.55)$ & $387(9.73)$ & $441(11.00)$ \\
\hline High & $478(26.88)$ & $398(23.23)$ & $235(5.91)$ & $440(10.97)$ \\
\hline \multicolumn{5}{|l|}{ Employment type } \\
\hline Not employed & 395 (28.66) & $177(15.39)$ & $1171(36.29)$ & $324(11.52)$ \\
\hline Full-time & $772(56.02)$ & $1060(92.17)$ & $1194(37.00)$ & $2590(92.07)$ \\
\hline Part-time & $167(12.12)$ & $48(4.17)$ & $662(20.51)$ & $49(1.74)$ \\
\hline Vocational Training & $36(2.61)$ & $22(1.91)$ & $87(2.70)$ & $95(3.38)$ \\
\hline Marginally Employed & $8(0.58)$ & $6(0.52)$ & $90(2.79)$ & $40(1.42)$ \\
\hline \multicolumn{5}{|l|}{ ST unemployment } \\
\hline Yes & $341(19.02)$ & $241(13.98)$ & $202(4.96)$ & $211(5.16)$ \\
\hline No & $1452(80.98)$ & $1483(86.02)$ & $3872(95.04)$ & $3882(94.84)$ \\
\hline \multicolumn{5}{|l|}{ LT unemployment } \\
\hline Yes & $114(6.36)$ & $57(3.31)$ & $50(1.23)$ & 85 (2.08) \\
\hline No & $1679(93.64)$ & $1667(96.69)$ & $4024(98.77)$ & 4008 (97.92) \\
\hline \multicolumn{5}{|l|}{ Unemployed 1993} \\
\hline Yes & 327 (19.87) & $207(5.49)$ & $185(12.04)$ & $219(5.76)$ \\
\hline No & $1319(80.13)$ & $3565(94.51)$ & $1351(87.96)$ & $3583(94.24)$ \\
\hline \multicolumn{5}{|l|}{ Unemployed 1994} \\
\hline Yes & $325(20.41)$ & $204(5.65)$ & $218(14.45)$ & $272(7.57)$ \\
\hline No & $1267(79.59)$ & 3407 (94.35) & $1291(85.55)$ & $3323(92.43)$ \\
\hline \multicolumn{5}{|l|}{ Unemployed 1995} \\
\hline Yes & $274(17.96)$ & $210(14.22)$ & $155(4.54)$ & $242(7.06)$ \\
\hline No & $1252(82.04)$ & $1267(85.78)$ & $3257(95.46)$ & $3184(92.94)$ \\
\hline \multicolumn{5}{|l|}{ Unemployed 1996} \\
\hline Yes & 254 (17.39) & $169(12.57)$ & $186(5.70)$ & $229(7.13)$ \\
\hline No & $1207(82.61)$ & $1176(87.43)$ & $3078(94.30)$ & $2983(92.87)$ \\
\hline
\end{tabular}

ST unemployment: registered unemployed in 1991 or 1992, LT unemployment: registered unemployed in 1991 and $1992 ;$ N.B. The data for the control variables (age, household income, partnership status, education, employment type) and social context comes from wave 1992

„How would you describe your current health?”. The 5point scale -1 (very good) to 5 (bad) - was inverted so that higher values reflected better self-rated health. This item was asked infrequently in the GSOEP from 1992 onwards; we used the data from 1992, 1994 and 1996 to reflect the time shortly after German reunification.

Life satisfaction was measured using the item „How satisfied are you with your life overall?". An 11-point scale of $O$ (completely dissatisfied) to 10 (completely satisfied) was used, so that higher values reflected greater life satisfaction. This item was asked annually, so data from the waves 1992 to 1996 was used.

Unemployment was measured by asking "Are you officially registered unemployed at the Federal Employment Agency?", with yes or no as possible answers. For each year (1991-1996) this variable was recoded to 1 for 
unemployed and 0 as not unemployed. To reflect unemployment directly after reunification (1991 \& 1992) two dummy-coded variables were computed: short-term unemployment $(1=$ unemployed in either years, $0=$ not unemployed during either, $0=$ unemployed in both) and long-term unemployment ( $1=$ unemployed both years, $0=$ not unemployed during either, $0=$ unemployed in either years).

Older age [8] as well as lower income and education [3] are associated with worse health in unemployed individuals. Also, traditional gender roles in respect to employment have been shown to be of importance $[40,43]$. Taking a similar approach to previous studies (e.g., [19]), the following were included as control variables in all analyses: age, household income, education and partnership status. Values from wave 1992 were used for the variables age (years), household income (Euros), gender $(1=$ female, $0=$ male), partnership status $(1=$ in partnership, $0=$ not in partnership), education (contrast $1: 1=$ medium, $0=$ low, $0=$ high; contrast $2: 1=$ high, $0=$ low, $0=$ medium $)$ and social context $(1=$ East, $0=$ West $)$.

\section{Statistical analysis}

To address the current research question latent growth modelling (LGM) was conducted with the Lavaan package [47] in $\mathrm{R}$ version 3.6.2 [48]. Growth analysis "attempt $[\mathrm{s}]$ to estimate between-person differences in within-person change" [49]. Recently LGM has been drawing on confirmatory factor analysis and structural equation modelling methods in a two-stage process. First, multiple measurement points of the outcome are fitted to latent factors of intercept (i.e. baseline value) and slope (i.e. growth). In the second stage, additional e.g. inter-person - variables are entered as predictors of the longitudinal growth trajectories $[49,50]$. See Fig. 1 for a visualization of the present statistical models. LGMs were computed separately for each health outcome (self-rated health and life satisfaction). The models were run with the whole sample to address hypotheses 1 and 2 and then separately by gender to address hypothesis 3.

While growth modelling is very flexible, some basic requirements need to be met. First, similar to other statistical analyses, an adequate sample is required [49] with a few thousand participants, this criterion was met in the present data.

Second, while there is no precise rule of thumb, the use of a minimum of three waves is generally advocated, with more data naturally offering more accurate models [49]. Again, this criterion was fulfilled, as the present study used data from 1992 to 1996 (i.e. three waves for self-rated health and five waves for life satisfaction). To account for the difference in number of time points between the outcome variables, we also ran adjusted

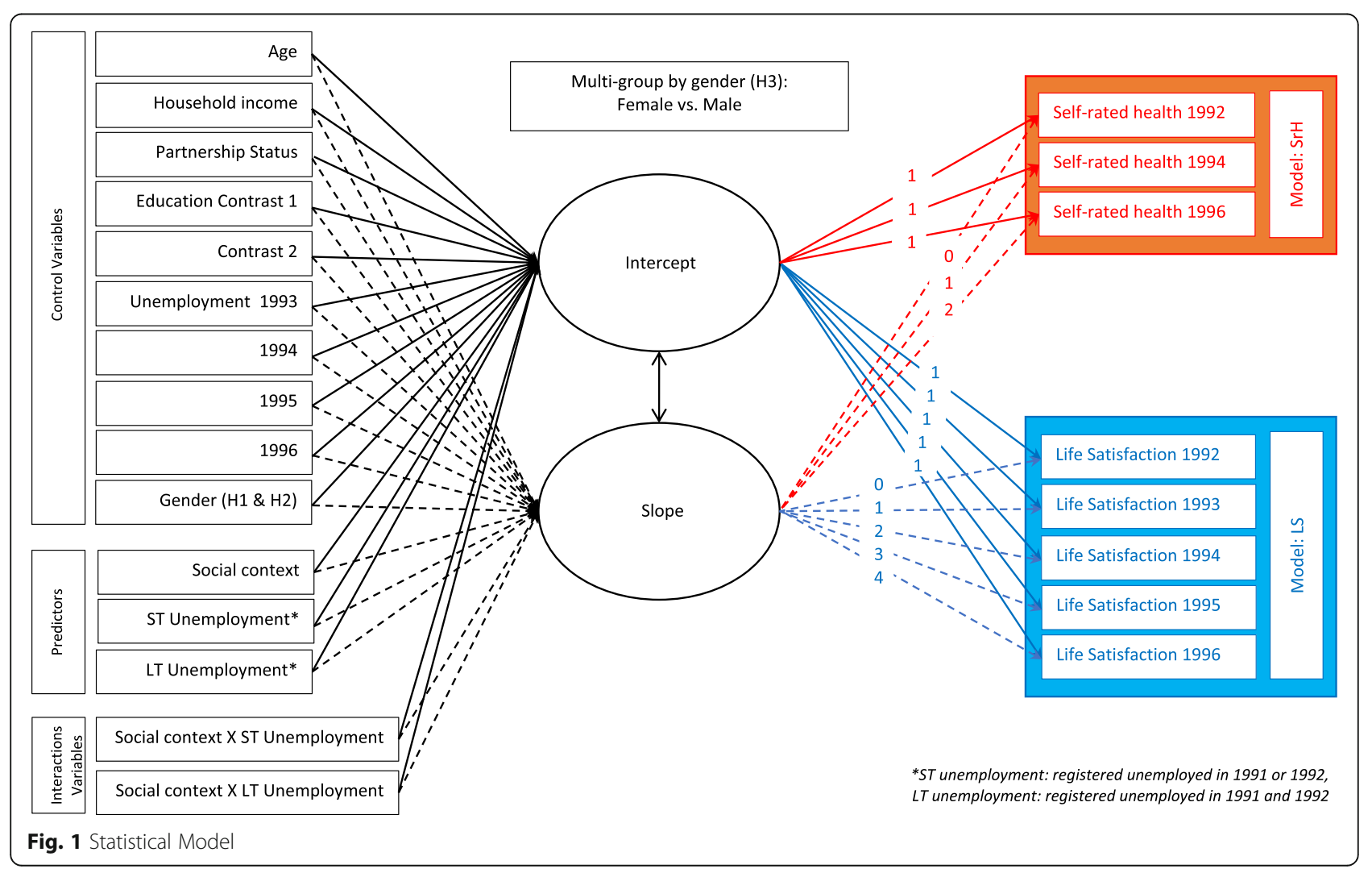


models with life satisfaction from the waves 1992, 1994 and 1996 only. The pattern of associations did not change, only the effect sizes reduced from the three- to five-wave models. Also, in the three-wave latent growth models (LGMs), the interaction social context and longterm unemployment was significant in the male sample and this became non-significant in the five-wave LGMs. As Curran et al. [49] suggest that model accuracy increases with more data, the five-wave models are used for all analyses.

Similar to previous studies [51] we assumed a linear progression and therefore fixed the intercept values at 1.0 and the slope values at 0.0, 1.0, 2.0 and 0.0, 1.0, 2.0,
3.0, 4.0 for self-rated health and life satisfaction respectively. The final criterion was also fulfilled, namely the outcome measures being continuous and normally distributed [49].

To evaluate the models, $\mathrm{Hu}$ and Bentler's [52] guidelines for model fit indices were used: Root Mean Squared Error of Approximation (RMSEA) $<.06$, Comparative Fit Index (CFI) $>.95$ and Standardized Root Mean Square Residual (SRMR) <.08. For model comparisons the Bayesian Information Criterion (BIC) and the Akaike Information Criterion (AIC) were used to rank order models, with the lowest BIC and AIC values indicating better models [49].

Table 2 Results of latent growth models (LGM) by total, female, and male sample (standardized $\beta$-values)

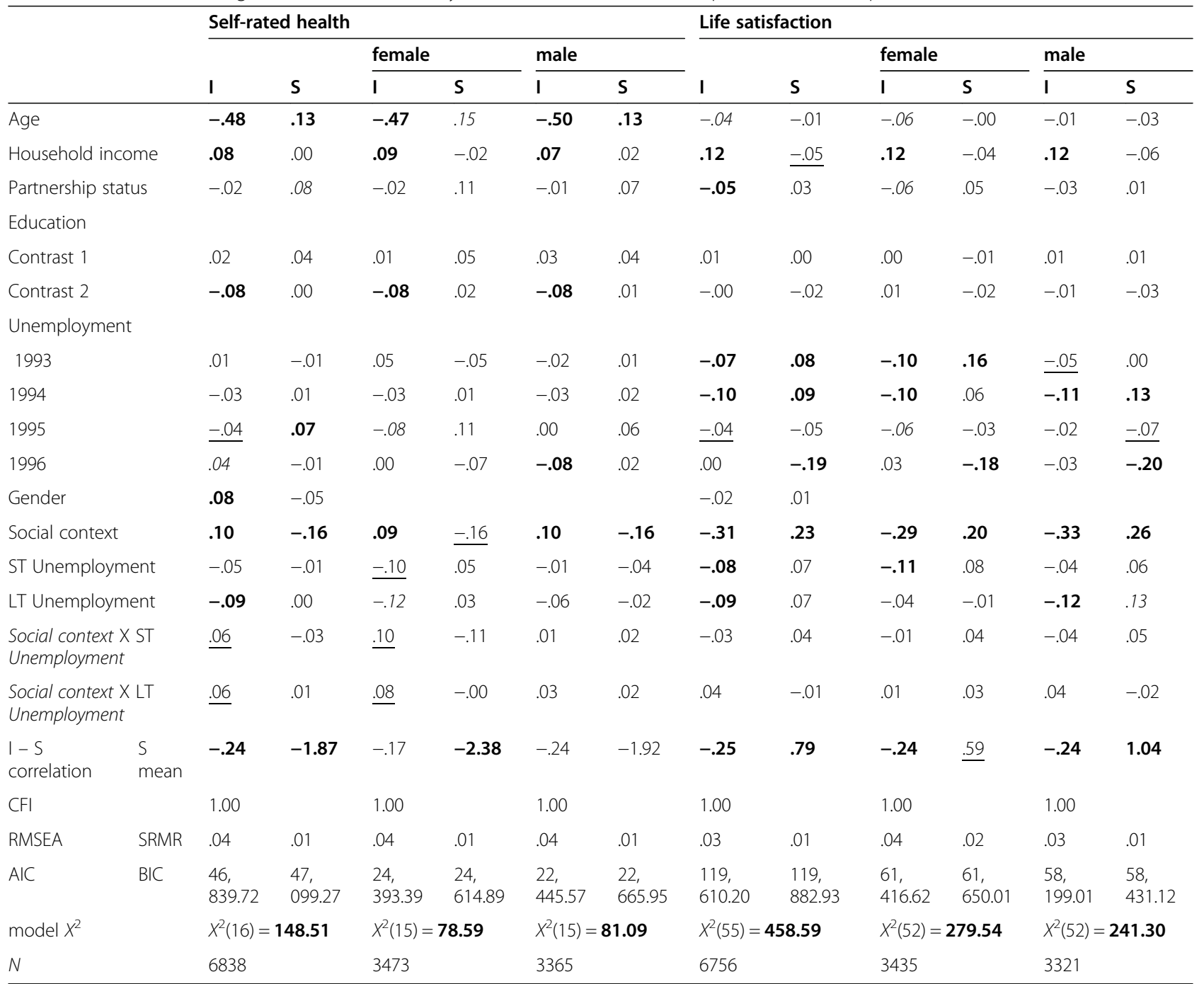

Test significance: bold: $\boldsymbol{p}<. \mathbf{0 0 1}$, italics: $p<.01$, underlined: $\mathrm{p}<.05 ;$ ST unemployment: registered unemployed in 1991 or $1992 ;$ LT unemployment: registered unemployed in 1991 and 1992; I: Intercept; S: Slope; RMSEA: root mean squared error of approximation; CFI: comparative fit index; SRMR: Standardized Root Mean Square Residual; BIS: Bayesian Information Criterion; AIC: Akaike Information Criterion; Analyses were also run on a subsample, retaining full-time, part-time and not employed participants. As the effect sizes and directions did not change drastically, the broader sample was retained 


\section{Results}

To gain an initial understanding of the predictor and outcome variables Pearson correlations were run separately by gender (see Additional file 1).

For all LGMs the fit indices showed a very good fit (see Table 2). The associations (effect size and significance) between control, predictor and outcome variables did not alter greatly when the interaction terms were entered into the models, therefore only the values of the models with interaction terms are reported.

Of the control variables, age was the strongest predictor of self-rated health, while household income was the strongest predictor of life satisfaction. Greater age, but lower household income were associated with a lower intercept and steeper decline of both self-rated health and life satisfaction. Being in a partnership significantly predicted a worse starting point of life satisfaction. The highest versus lowest education was associated with a lower intercept in self-rated health. There were multiple but no consistent associations between unemployment in 1993-1996 and the health outcomes.

\section{Short- versus long-term unemployment}

Figures 2 and 3 show the descriptive trajectories of selfrated health and life satisfaction respectively. The descriptive trajectories of self-rated health were worse for participants reporting long-term, compared to no or short-term unemployment after reunification. The results from the LGMs with the whole sample supported this pattern, as only long-term unemployment was significantly related to a lower starting point of self-rated health.

For life satisfaction, the descriptive trajectories had a lower starting point for short- and long-term compared to no unemployment. The LGMs supported this relationship, as both types of unemployment were significantly associated with a lower starting point of life satisfaction.
Thus, the effect of long- versus short-term unemployment on self-rated health was more negative, while the effects of short- and long-term unemployment were similar on life satisfaction.

\section{Social context}

The descriptive trajectories of both health outcomes were generally lower in the West versus East German sample. The results from the LGMs with the whole sample confirmed a significant direct effect of social context on both aspects of health. East Germans showed a higher starting point of self-rated health and more negative trajectories, but a lower starting point of life satisfaction and more positive trajectories. Notably the effect was stronger with life satisfaction compared to self-rated health.

To address $H 2$ the interaction effect of social context and unemployment was inspected. West German men and women who were unemployed long-term after reunification had lower starting points of self-rated health and their trajectories did not catch up to the other groups. The LGM showed significant interaction effects of both types of unemployment in respect to the intercept of self-rated health, with reported unemployment being associated with a higher starting point in the East German sample.

The descriptive trajectories of life satisfaction showed better satisfaction in persons who reported no unemployment compared to short- and long-term unemployment. However, the interaction on life satisfaction did not reach statistical significance in the LGMs. Thus, $H 2$ was only supported in respect to selfrated health and not life satisfaction.

\section{Gender effects}

Next, the interaction term - social context and unemployment after reunification - was examined in men and women separately. The descriptive trajectories of West German men and women who reported long-term

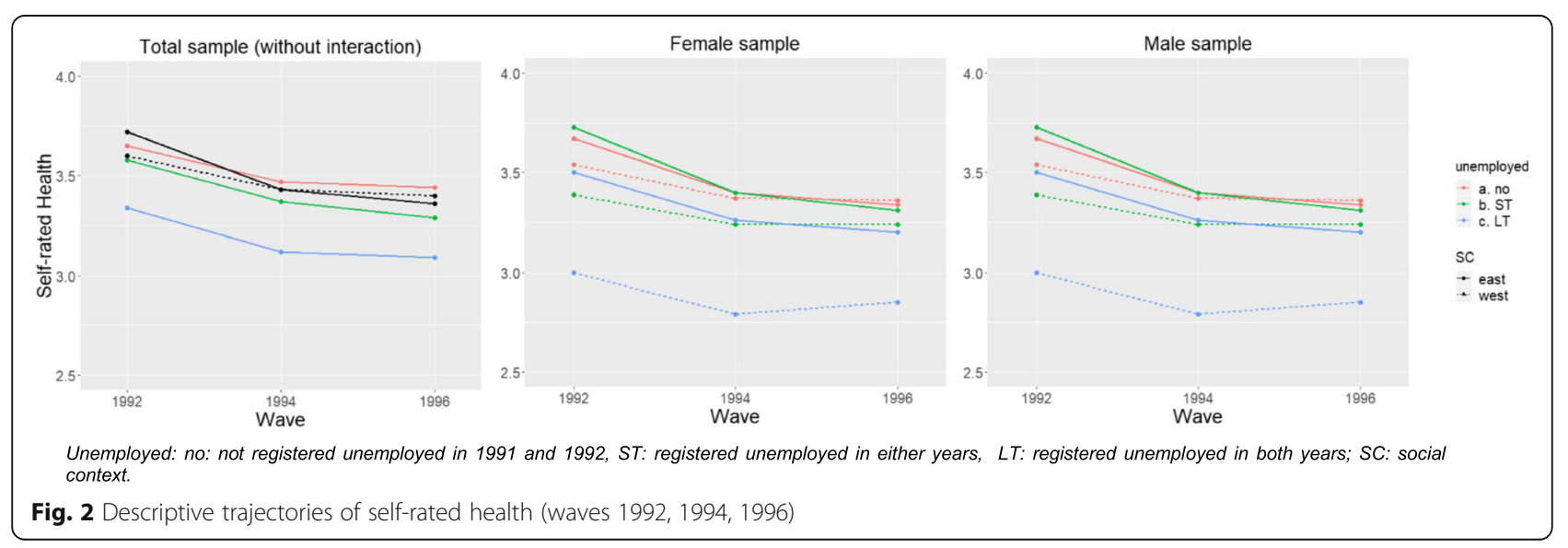




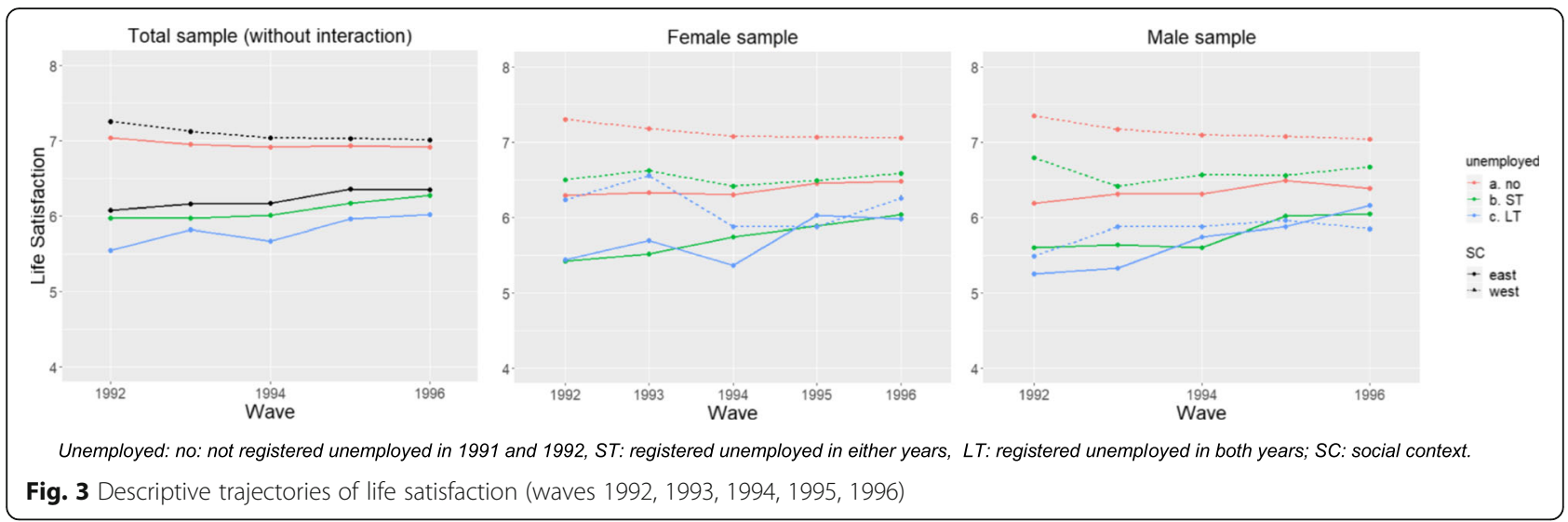

unemployment showed a lower intercept of self-rated health. The LGMs revealed that the interaction of social context with unemployment was only significantly positively associated with the intercept of self-rated health in the female, but not the male sample. West German women reported the lowest starting point for self-rated health following unemployment. This was the case for both short- and long-term unemployment after reunification. The fit indices however only confirmed that the model with long- versus short-term unemployment was a better fit in the female than the male sample.

The descriptive trajectories of life satisfaction divided by gender did not reveal a clear interaction effect of social context and unemployment and the LGMs also did not show significant associations between the interaction and life satisfaction in either gender.

Thus, $H 3$ was only confirmed in relation to self-rated health and not life satisfaction.

\section{Discussion}

We examined the interplay of gender, social context and job loss on long-term effects of health in a period and social context where drastic unemployment divided a population. The findings revealed the importance of social context in the impact of unemployment and that this effect was not consistent across different health outcomes. While we found social context to be the strongest predictor of both baseline and the development of health, the most notable finding was the significant interaction of social context and unemployment with baseline self-rated health in the female sample. Data following German reunification was analysed, because East Germans were confronted with a major change in their employment system and they collectively faced a dramatic increase in unemployment [27]. This was also seen in this sample, where East compared to West Germans were 3.2 times as likely to be unemployed in either 1991 or 1992 and 2.9 times as likely to be unemployed in both years.
Similar to previous findings [43, 44], the interactions between unemployment, gender and psychological distress were dependent on the social context. We expected East German women to find it more difficult to recover following unemployment, because they would assign greater importance to employment compared to their West German counterparts. Instead, we found that the West German, female sample showed lower baseline self-rated health following unemployment and did not recover to the level of the other groups. Around the time of the German reunification, the majority of West German women followed traditional gender roles and were either housewives or in part-time employment [39]. Perhaps we drew on a subset of West German women: by working and therefore breaking with traditional gender roles, these women would have been more modern and independent than the average West German woman. Indeed, in the present West German, female sample, those who were unemployed in both 1991 and 1992 were 5.9 times less likely to be in a partnership compared to their East German counterparts. Being married has a protective effect on the mental health of unemployed women [53] - not being able to depend on a partner's income would make them more reliant on their own employment. Thus, many more factors may have been coupled with their unemployment and given this event an even greater significance than mere financial strain; for instance, the pressures of succeeding against the odds in a male dominated society and, as a result of their job loss, apparently 'failing'. In line with the view that unemployment and health have a reciprocal relationship [30], West German women possibly exhibited worse health prior to their job loss due to surrounding factors. Having said that, this is beyond the scope of the present investigation and future research may want to consider such aspects in more detail.

In comparison, the East German, female sample reacted more similarly to the male samples from both social contexts. In former East Germany, gender equality 
in income and employment was common practice [37]. Traditional gender roles were not the norm [27] and women were able to easily combine being a mother, wife and worker [38]. It follows then that after the reunification, like their male counterparts, East German women would have desired and felt obligated to continue their employment.

The trend we found was that East Germans and West German men reported a gradual decline in their selfrated health. Our results confirmed that high regional unemployment not only impacts those directly affected, but also employed persons in those areas $[3,35]$.

\section{Short- versus long-term unemployment}

The present results confirmed that long-compared to short-term unemployment had a stronger impact on self-rated health but no difference was found in relation to life satisfaction $[3,6,16,18]$. Long-term unemployment has often been defined as six to 12 months or more [21, 22], whereas we defined short-term unemployment as being registered unemployed in one year and long-term unemployment as being registered unemployed in two consecutive years. The only association we found with short-term unemployment were significantly, lower baseline values of life satisfaction. As the other associations with the trajectories of health were found with long-term unemployment, it appears that the definition of long-term unemployment as more than one year is not sufficient. Similarly Milner et al. [23] found that health risks were not constant during a period of unemployment and Flatau et al. [7] found that compared to men, women's mental health fluctuated more frequently within the first year of unemployment. As we did not measure unemployment length in smaller increments, their results may explain why the female sample showed a lower starting point on both health outcomes following short-term unemployment. Namely, that following short-term job loss the women adjusted to the experience of unemployment and therefore their satisfaction levels were not as affected by further unemployment.

Instead we found that men who experienced longterm unemployment reported lower initial life satisfaction and showed positive trajectories. The male sample appeared to adjust to short-term unemployment more easily, but then were more affected by long-term unemployment. Drawing on the set-point theory [11, 12], job loss was proposed to throw persons from their equilibrium of health, to then recover to their original, 'setpoint'. Our results in relation to life satisfaction support set-point theory and indicated a recovery in men following long-term unemployment.

On the other hand, in relation to self-rated health both men and women who faced long-term unemployment reported significantly lower baseline values and their trajectories did not recover to the values of their employed counterparts. Our findings are parallel to the findings of Clark et al. [6], who reported that unemployed persons did not return to their baseline values of well-being long after the end of their unemployment. In respect to selfrated health, we also found that long-term unemployment established a new, lower set-point and the former levels were not recovered. Thus, our findings indicate that men facing long-term unemployment were able to recover in terms of life satisfaction, but their self-rated health showed a longer term setback.

\section{Strengths, limitations and future directions}

One strength of the current investigation is that - unlike previous unemployment research - two health constructs as well as two social contexts were examined separately. As our findings revealed different effects for selfrated health and life satisfaction as well as across social contexts this approach was indeed beneficial.

Another strength is that long-term unemployment was measured as being registered unemployed in two consecutive years, while generally it has been defined as only more than one year [22]. Due to the operationalization of the short- and long-term unemployment construct, it is possible that participants were not unemployed continuously for one or two years, respectively. However, our analyses revealed greater effects for long-term unemployment and only minimal associations with shortterm unemployment and support the importance of extending the definition of long-term unemployment. Further, while the unemployment measure can clearly distinguish unemployment from other types of nonemployment (e.g., retirement, maternity leave), it possesses ambiguity in terms of employment type (e.g., fulltime, part-time, vocational training).

As the case numbers would have been too low to consider the numerous predictor variables, the current sample did not solely consist of individuals who were solely unemployed or reemployed between 1992 to 1996. Significant effects were found above and beyond controlling for unemployment in the following years. Thus, the current approach can in fact be seen as a strength, namely that this study considered a non-induced phenomenon of mass unemployment.

Further, the effect sizes of the direct and interaction effects of unemployment were relatively small. The small effects of negative life events are well known(e.g., [54]) and indeed that the magnitude of the impact drops quickly after one year [55]. In turn, the fact that we did find long-term effects highlights the significance that unemployment has on health. 


\section{Conclusions}

We analysed data from a particularly stark turning point in German history, where mass unemployment was widespread and divided the population. Certainly, this was not the last wave of such mass unemployment in Germany or other parts of the world and so the present findings provide guidance to similar circumstances. Social context was the strongest predictor of the development of health, yet the most notable finding was that West as opposed to East German women reported lower baseline self-rated health. At the time, this group would have been expected to be least affected by the economic crisis. Yet it appears that when this group - that was likely already burdened by numerous other stressors, breaking with traditional gender roles and fighting against the odds in a male dominated society - were confronted with unemployment they faced just one too many stressors. This highlights that during an economic crisis, policies makers and health providers should not only target those most directly affected economically but should also focus on populations who already carry a higher burden and may then simply be tipped over the edge.

\section{Supplementary Information}

The online version contains supplementary material available at https://doi. org/10.1186/s12889-021-10324-8

Additional file 1. AF1. Correlation matrix of predictor and outcome

variables (female sample above, male sample below the axis).

\section{Abbreviations}

GSOEP: German Socio-Economic Panel; LGM: Latent growth model; RMSEA: Root mean squared error of approximation; CFI: Comparative fit index; SRMR: Standardized Root Mean Square Residual; BIC: Bayesian Information Criterion; AIC: Akaike Information Criterion

\section{Acknowledgements}

Not applicable.

\section{Authors' contributions}

HM, SS1 (Sven Speerforck), GS, MEB, EB, and SS2 (Silke Schmidt) conceived the research idea. LA designed the study, analysed the data, and drafted the manuscript. SH HM, and SS1 (Silke Schmidt) provided major initial criticism of the manuscript. TG, CU, SS1 (Sven Speerforck), GS, MEB, and EB contributed to subsequent revisions of the manuscript. All authors reviewed and approved the final version the manuscript for publication.

\section{Funding}

This work was supported by the German Federal Ministry of Education and Research, Berlin [grant number 01UJ1911DY]. The funder had no involvement in study design, data collection and analysis, decision to publish, or preparation of the manuscript. Open Access funding enabled and organized by Projekt DEAL.

\section{Availability of data and materials}

The datasets generated and/or analysed during the current study are available in the repository of the German Institute for Economic Research, https://www.diw.de/en/diw_02.c.222843.en/ forms.html.

\section{Ethics approval and consent to participate}

The study protocols of SOEP-Core were approved by the German Institute for Economic Research $[45,46]$ and written informed consent was obtained from each subject [56-61].

\section{Consent for publication}

Not applicable.

\section{Competing interests}

The authors declare that they have no competing interests.

\section{Author details}

${ }^{1}$ Department of Health and Prevention, University of Greifswald, Robert-Blum-Str. 13, 17489 Greifswald, Germany. ${ }^{2}$ Department of Psychiatry and Psychotherapy, Leipzig University Medical Center, Liebigstraße 18, Haus

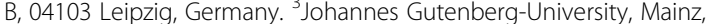
Department of Psychosomatic Medicine and Psychotherapy, University Medical Center, Untere Zahlbacher Str. 8, 55131 Mainz, Germany.

Received: 6 November 2020 Accepted: 19 January 2021

Published online: 04 February 2021

\section{References}

1. Pearlin LI, Menaghan EG, Lieberman MA, Mullan JT. The stress process. J Health Soc Behav. 1981;22:337. https://doi.org/10.2307/2136676

2. Paul Kl, Batinic B. The need for work: Jahoda's latent functions of employment in a representative sample of the German population. J. Organiz. Behav. 2010;31:45-64. https://doi.org/10.1002/job.622 .

3. McKee-Ryan F, Song Z, Wanberg CR, Kinicki AJ. Psychological and physical well-being during unemployment: a meta-analytic study. J Appl Psychol. 2005:90:53-76. https://doi.org/10.1037/0021-9010.90.1.53

4. Winkelmann L, Winkelmann R. Why are the unemployed so unhappy? Evidence from panel data. Zurich Open Repository and Archive. 1998;65:115.

5. Monroe SM, Harkness KL. Life stress, the "kindling" hypothesis, and the recurrence of depression: considerations from a life stress perspective. Psychol Rev. 2005:112:417-45. https://doi.org/10.1037/0033-295X.112.2.417

6. Clark AE, Georgellis Y, Lucas RE, Diener E. Unemployment alters the setpoint for life satisfaction. Psychol Sci. 2002;1:8-13. https://doi.org/10.1111/j. 0963-7214.2004.01501002.x

7. Flatau P, Galea J, Petridis R. Mental health and wellbeing and unemployment. Aust Econ Rev. 2000;33:161-81. https://doi.org/10.1111/ 1467-8462.00145

8. Luhmann M, Eid M. Does it really feel the same? Changes in life satisfaction following repeated life events. J Pers Soc Psychol. 2009;97:363-81. https:// doi.org/10.1037/a0015809

9. Post RM. Transduction of psychosocial stress into the neurobiology of recurrent affective disorder. Am J Psychiatr. 1992;149:999-1010.

10. Spence R, Bunn A, Nunn S, Hosang GM, Kagan L, Fisher HL, et al. Measuring life events and their association with clinical disorder: a protocol for development of an online approach. JMIR Res Protoc. 2015;4:1-10. https:// doi.org/10.2196/resprot.4085

11. Costa PT, McCrae RR. Influence of extraversion and neuroticism on subjective well-being: happy and unhappy people. J Pers Soc Psychol. 1980; 38:668-78.

12. Headey B. Happiness: Revising Set Point Theory and Dynamic Equilibrium Theory to Account for Long Term Change. In: DIW Discussion Papers, No. 607; 2006. p. 1-25

13. Headey B, Wearing A. Personality, life events, and subjective Weil-being: toward a dynamic equilibrium model. J Pers Soc Psychol. 1989;57:731-9.

14. Graetz B. Health consequences of employment and unemployment: longitudinal evidence for young men and women. Soc Sci Med. 1993;36: 715-24. https://doi.org/10.1016/0277-9536(93)90032-Y

15. World Health Organization. Constitution of the world health organization. 2014. https://www.who.int/governance/eb/who_constitution_en.pdf. Accessed 2 Feb 2020.

16. Paul Kl, Moser K. Incongruence as an explanation for the negative mental health effects of unemployment: meta-analytic evidence. J Occup Organ Psychol. 2006;79:595-621. https://doi.org/10.1348/096317905X70823

17. Herber G-C, Ruijsbroek A, Koopmanschap M, Proper K, van der Lucht F, Boshuizen $\mathrm{H}$, et al. Single transitions and persistence of unemployment are 
associated with poor health outcomes. BMC Public Health. 2019;19:740. https://doi.org/10.1186/s12889-019-7059-8.

18. Berth H, Förster P, Petrowski K, Stöbel-Richter $Y$, Balck F. Geschlechterdifferenzen in den Gesundheitsfolgen von Arbeitslosigkeit. Ergebnisse der Sächsischen Längsschnittstudie. Gesundheit im gesellschaftlichen Wandel. Altersspezifik und Geschlechterrollen. 2006:78-92.

19. Zenger M, Brähler E, Berth H, Stöbel-Richter Y. Unemployment during working life and mental health of retirees: results of a representative survey. Aging Ment Health. 2011;15:178-85. https://doi.org/10.1080/13607863.2010.508775

20. Berth H, Förster P, Balck F, Brähler E, Stöbel-Richter Y. Was bedeutet Langzeitarbeitslosigkeit für junge Erwachsene?: Ergebnisse der Sächsischen Längsschnittstudie. Verhaltenstherapie \& Psychosoziale Praxis. 2008;40:87-97.

21. Dooley D, Catalano R, Rook KS. Personal and aggregate unemployment and psychological symptoms. J Soc Issues. 1988;44:107-23. https://doi.org/10. 1111/j.1540-4560.1988.tb02094.x

22. Brief AP, Konovsky MA, Goodwin R, Link K. Inferring the meaning of work from the effects of unemployment. J Appl Social Pyschol. 1995;25:693-711. https://doi.org/10.1111/j.1559-1816.1995.tb01769.x

23. Milner A, Page A, LaMontagne AD. Long-term unemployment and suicide: a systematic review and meta-analysis. PLoS One. 2013;8:e51333. https://doi. org/10.1371/journal.pone.0051333 .

24. Liebig S, Buchinger L, Entringer T, Kühne S. Ost- und Westdeutschland in der Corona-Krise: Nachwendegeneration im Osten erweist sich als resilient: DIW - Deutsches Institut für Wirtschaftsforschung; 2020.

25. Sackmann R, Weymann A, Wingens M. Die Generation der Wende: Berufsund Lebensverläufe im sozialen Wandel. 1st ed. Wiesbaden: (c) Westdeutscher Verlag GmbH; 2000.

26. Bundesagentur für Arbeit. Arbeitsmarkt 1991: Arbeitsmarktanalyse für die alten und neuen Bundesländer. Nürnberg; 1992.

27. Struck O, Rasztar M, Sackmann R, Weymann A, Wingens M. Die Generation der Wendezeit:erfolgreich, nüchtern und enttäuscht. Arbeitspapier / Sfb 186, 49. Bremen: Universität Bremen; 1998.

28. Mayer KU. Lebensverlauf. In: Schäfers B, Zapf W, editors. Handwörterbuch zur Gesellschaft Deutschlands. 2nd ed. Opladen: Leske + Budrich; 2001. p. 446-60. https://doi.org/10.1007/978-3-322-94976-9_39

29. Booth M. Die Entwicklung der Arbeitslosigkeit in Deutschland; 2010.

30. Böckerman P, Ilmakunnas P. Unemployment and self-assessed health: evidence from panel data. Health Econ. 2009;18:161-79. https://doi.org/10. 1002/hec.1361

31. Brydsten A, Gustafsson PE, Hammarström A, San SM. Does contextual unemployment matter for health status across the life course? A longitudinal multilevel study exploring the link between neighbourhood unemployment and functional somatic symptoms. Health Place. 2017;43: 113-20. https://doi.org/10.1016/j.healthplace.2016.11.014

32. Buffel V, Missinne S, Bracke P. The social norm of unemployment in relation to mental health and medical care use: the role of regional unemployment levels and of displaced workers. Work Employ Soc. 2017;31:501-21. https:// doi.org/10.1177/0950017016631442

33. Oesch D, Lipps O. Does unemployment hurt less if there is more of it around? A panel analysis of life satisfaction in Germany and Switzerland. Eur Sociol Rev. 2013;29:955-67. https://doi.org/10.1093/esr/jcs071

34. Turner JB. Economic context and the health effects of unemployment. J Health Soc Behav. 1995;36:213. https://doi.org/10.2307/2137339.

35. Flint E, Shelton N, Bartley M, Sacker A. Do local unemployment rates modify the effect of individual labour market status on psychological distress? Health Place. 2013;23:1-8. https://doi.org/10.1016/j.healthplace.2013.04.004

36. Clark AE, Knabe A, Rätzel S. Boon or bane? Others' unemployment, wellbeing and job insecurity. Labour Econ. 2010;17:52-61. https://doi.org/10. 1016/j.labeco.2009.05.007 .

37. Lüschen G, Geling O, Janßen C, Kunz G, von Dem Knesebeck O. After unification: gender and subjective health status in east and West Germany. Soc Sci Med. 1997:44:1313-23. https://doi.org/10.1016/S0277-9536(96)002596.

38. Stöbel-Richter $Y$, Berth $H$, Brähler $E$, Zenger M. Familiengründung als individuelles und gesellschaftliches Lebensereignis. In: Berth $H$, Brähler $E$, Zenger M, Stöbel-Richter Y, editors. Innenansichten der Transformation: 25 Jahre Sächsische Längsschnittstudie (1987-2012). Gießen: PsychosozialVerlag; 2012. p. 321-40.

39. Spellerberg A. Frauen zwischen Familie und Beruf. EconStor Open Access Articles. 1996:99-120.
40. van der Meer PH. Gender, unemployment and subjective well-being: why being unemployed is worse for men than for women. Soc Indic Res. 2014 115:23-44. https://doi.org/10.1007/s11205-012-0207-5 .

41. Forret ML, Mainiero LA, Sullivan SE. Gender role differences in reactions to unemployment: exploring psychological mobility and boundaryless careers. J Organiz Behav. 2010;31:647-66. https://doi.org/10.1002/job.703.

42. Bundesagentur für Arbeit, Statistik/Arbeitsmarktberichterstattung. Die Arbeitsmarktsituation von Frauen und Männern 2018. Nürnberg; 07/2019.

43. Strandh M, Hammarström A, Nilsson K, Nordenmark M, Russel H. Unemployment, gender and mental health: the role of the gender regime. Sociol Health IIIn. 2013;35:649-65. https://doi.org/10.1111/j.1467-9566.2012. 01517.x.

44. Hammarström A, Gustafsson PE, Strandh M, Virtanen P, Janlert U. It's no surprise! Men are not hit more than women by the health consequences of unemployment in the northern Swedish cohort. Scand J Public Health. 2011;39:187-93. https://doi.org/10.1177/1403494810394906

45. Liebig S, Goebel J, Schröder C, Grabka M, Richter D, Schupp J, et al. Soziooekonomisches Panel (SOEP), Daten der Jahre 1984-2018: SOEP SocioEconomic Panel Study; 2019.

46. Goebel J, Grabka MM, Liebig S, Kroh M, Richter D, Schröder C, Schupp J. The German socio-economic panel (SOEP). Jahrbücher für Nationalökonomie und Statistik. 2019;239:345-60. https://doi.org/10.1515/ jbnst-2018-0022.

47. Rosseel Y. lavaan: An R Package for Structural Equation Modeling. J Stat Software. 2012;2(48):1-36. https://doi.org/10.18637/jss.v048.i02.

48. Core R. Team. R: A language and environment for statistical computing. Vienna, Austria: R Foundation for statistical Computing; 2019.

49. Curran PJ, Obeidat K, Losardo D. Twelve frequently asked questions about growth curve modeling. J Cogn Dev. 2010;11:121-36. https://doi.org/10. 1080/15248371003699969

50. Lance CE, Vandenberg RJ. Latent growth models of individual change: the case of newcomer adjustment. Organ Behav Hum Decis Process. 2000;83: 107-40. https://doi.org/10.1006/obhd.2000.2904

51. Lucas RE, Clark AE, Georgellis $Y$, Diener E. Reexamining adaptation and the set point model of happiness: reactions to changes in marital status. J Pers Soc Psychol. 2003;84:527-39. https://doi.org/10.1037/0022-3514.84.3.527

52. Hu L-t, Bentler PM. Cutoff criteria for fit indexes in covariance structure analysis: conventional criteria versus new alternatives. Struct Equ Model Multidiscip J. 1999;6:1-55. https://doi.org/10.1080/10705519909540118 .

53. Artazcoz L, Benach J, Borrell C, Cortès I. Unemployment and mental health: understanding the interactions among gender, family roles, and social class. Am J Public Health. 2004;94:82-8. https://doi.org/10.2105/ajph.94.1.82

54. Kanner AD, Coyne JC, Schaefer C, Lazarus RS. Comparison of two modes of stress measurement: daily hassles and uplifts versus major life events. J Behav Med. 1981;4:1-39. https://doi.org/10.1007/bf00844845

55. Suh E, Diener E, Fujita F. Events and subjective Weil-being: only recent events matter. J Pers Soc Psychol. 1996;70:1091-102.

56. Infratest Sozialforschung. SOEP 1990/91 - Methodenbericht Ostdeutschland zu den Befragungsjahren 1990-1991 (Welle 1/2 - Ost) des Soziooekonomischen Panels. SOEP Survey Papers 14: Series B. Berlin; 2011.

57. Infratest Sozialforschung. SOEP 1992 - Methodenbericht zum Befragungsjahr 1992 (Welle 9/West und Welle 3/Ost) des Soziooekonomischen Panels. SOEP Survey Papers 21: Series B. Berlin; 2011.

58. Infratest Sozialforschung. SOEP 1993 - Methodenbericht zum Befragungsjahr 1993 (Welle 10/West und Welle 4/Ost) des Soziooekonomischen Panels. SOEP Survey Papers 23: Series B. Berlin; 2011.

59. Infratest Sozialforschung. SOEP 1994 - Methodenbericht ZuwandererBefragung (Teilstichprobe D1) zum Befragungsjahr 1994 (Welle 11) des Sozio-oekonomischen Panels. SOEP Survey Papers 26: Series B. Berlin; 2011.

60. Infratest Burke Sozialforschung. SOEP 1995 - Methodenbericht ZuwandererBefra-gung II (Zweitbefragung D1, Erstbefragung D2) zum Befragungsjahr 1995 (Welle 12) des Sozio-oekonomischen Panels. SOEP Survey Papers 28: Series B. Berlin; 2011.

61. Infratest Burke Sozialforschung. SOEP 1996 - Methodenbericht zum Befragungsjahr 1996 (Wellen 13/7/2) des Sozio-oekonomischen Panels. SOEP Survey Papers 29: Series B - Survey Reports (Methodenberichte). Berlin; 2011.

\section{Publisher's Note}

Springer Nature remains neutral with regard to jurisdictional claims in published maps and institutional affiliations. 